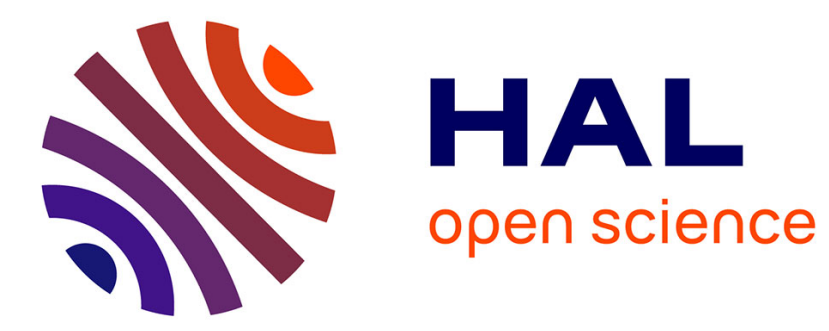

\title{
Developing a self-reporting method to measure pedestrian behaviors at all ages
}

Marie-Axelle Granié, Marjorie Pannetier, Ludivine Gueho

\section{To cite this version:}

Marie-Axelle Granié, Marjorie Pannetier, Ludivine Gueho. Developing a self-reporting method to measure pedestrian behaviors at all ages. Accident Analysis \& Prevention, 2013, 50 (1), p830-839. 10.1016/j.aap.2012.07.009 . hal-00849098

\section{HAL Id: hal-00849098 \\ https://hal.science/hal-00849098}

Submitted on $30 \mathrm{Jul} 2013$

HAL is a multi-disciplinary open access archive for the deposit and dissemination of scientific research documents, whether they are published or not. The documents may come from teaching and research institutions in France or abroad, or from public or private research centers.
L'archive ouverte pluridisciplinaire HAL, est destinée au dépôt et à la diffusion de documents scientifiques de niveau recherche, publiés ou non, émanant des établissements d'enseignement et de recherche français ou étrangers, des laboratoires publics ou privés. 
Marie-Axelle Granié, Marjorie Pannetier, Ludivine Guého, Developing a self-reporting method to measure pedestrian behaviors at all ages, Accident Analysis \& Prevention, Volume 50, January 2013, Pages 830-839

http://dx.doi.org/10.1016/j.aap.2012.07.009

Running head: Developing a self-reporting method to measure pedestrian behaviors at all ages

Developing a self-reporting method to measure pedestrian behaviors at all ages

\author{
Marie-Axelle Granié* \\ IFSTTAR-MA \\ 304 Chemin de la Croix Blanche \\ F-13300 Salon de Provence, France \\ * Corresponding author \\ marie-axelle.granie@inrets.fr \\ Phone : +33(0)4 90577979 \\ Fax : +33(0)4 90568618
}

Marjorie Pannetier

IFSTTAR-MA

304 Chemin de la Croix Blanche

F-13300 Salon de Provence, France

Ludivine Guého

IFSTTAR-MA

304 Chemin de la Croix Blanche

F-13300 Salon de Provence, France 
Developing a self-reporting method to measure pedestrian behaviors at all ages

\begin{abstract}
The objective of this study was to develop and validate a self-reporting scale to measure injury risk behaviors among pedestrians of all ages. The Pedestrian Behavior Scale (PBS) was developed that included 47 items enabling respondents to evaluate the frequency with which they had different types of pedestrian behaviors. The validation study was carried out on 343 participants (126 men and 217 women) between the ages of 15 and 78 . Factor analyses were used to differentiate between 4 axes. Factor 1, "transgression”, included items concerning offence of legal rules and errors. Factor 2 included "lapses" items. Factor 3 comprised "aggressive behavior" items and factor 4 included "positive behavior" items. A revised version of the PBS with 20 items was produced by selecting those items that loaded most strongly on the four factors. The 20-item version had good internal reliability. The effects of demographic and mobility variables on the PBS scores were investigated. This instrument will be useful in measuring the frequency of these different types of behaviors among the pedestrians who are most at risk, analyzing the psychological factors used to predict PBS scores and thus better adapt preventive actions to the different populations of vulnerable road users of all ages.

Keywords: pedestrian - behavior - violation - error - aggression - positive behaviors
\end{abstract}


Developing a self-reporting method to measure pedestrian behaviors at all ages

\section{Introduction}

Even though pedestrian exposure to traffic when crossing represents a small part of total walking activity, 11,000 of the 78,000 deaths in traffic accidents in the 23 OECD countries in 2006 concerned pedestrians (SafetyNet, 2009). In France, 535 pedestrians were killed and 5,523 seriously injured in traffic accidents in 2006 (ONISR, 2007). Therefore, understanding pedestrian behaviors when crossing remains a road safety challenge.

Tools for observing pedestrian behaviors, however, are few and far between. While ethological observation in road environment (Latrémouille et al., 2004; Zeedyk and Kelly, 2003), is still the best way of understanding the effect of environment on pedestrian behaviors in one given context (Sisiopiku and Akin, 2003), they do not provide a complete view of everyday pedestrian injury risk behaviors in different contexts.

Another method for studying pedestrian behaviors consists in using declared behavior questionnaires aimed at providing a self-report on travel and crossing practices (Evans and Norman, 1998; 2003; Yagil, 2000; Zhou and Horrey, 2010; Zhou et al., 2009). This kind of method permits to classify the wide ranging pedestrian behaviors into a system of behavioral factors (Elliott and Baughan, 2004). This method is likely to be beneficial for research investigating pedestrian safety, because it would provide a framework in which to study a number of important issues, such as which type of behaviors are involved in road accidents and what psychological mechanisms explained this behaviors. Few tools are available, however, and they often focus on a few transgressive behaviors by pedestrians when crossing. One of the most complete questionnaires is the one developed in the United Kingdom on adolescent pedestrian behaviors by Elliott and Baughan (2004), validated in New Zealand 
(Sullman and Mann, 2009), Spain (Sullman et al., 2011) and France (Abou et al., 2008). Based on a list of 43 behaviors judged to be dangerous by the experts and on a survey of 2,433 adolescents between the ages of 11 and 16, it identified 21 pedestrian behaviors, differentiated into 3 axes: unsafe street crossings, dangerous games in the street and planned protective behaviors. It cannot be used, however, to measure pedestrian behaviors in relation to the rules and some of the items are only adapted for an adolescent population, such as playing chicken during crossing behaviors. Based on this tool, a questionnaire measuring behaviors of pedestrians of all ages was developed in France and validated with adults (Granié, 2008) and adolescents (Granié, 2009). Using and developing the items from Elliott and Baughan (2004), its aim was to measure pedestrian behaviors in terms of endangerment and transgression. In its current design, however, this tool did not differentiate between errors and lapses in putting oneself in danger. This distinction made it possible to gain a more detailed understanding of behaviors with accident risks, depending on intentionality and the nature of the deviation from safe behavior.

A first differentiation of risk behaviors should indeed be made between violations intentional - and mistakes - unintentional - which have different psychological origins and require different mode of remediation (Reason et al., 1990b). Thus, mistakes involve failures of cognitive skills and could be corrected by educational campaigns and training courses. Transgressions involve motivational factors and should be only countered by altering attitudes of specific groups to specific kind of transgressive behaviors.

On a second level, two types of behaviors can be differentiated among mistakes: lapses and errors (Reason et al., 1990b). Lapses (slips and inattention) are defined as involuntary deviations in the action, ill-suited to the original intent. Errors concern failures in intent, illsuited to the situation. This concerns deficiencies in the decision-making or inferential processes involved in choosing an objective and/or the resources for achieving it. 
Among these errors, Reason (1987), after Rasmussen (1980; 1983), differentiated between two categories. Errors related to knowledge are produced when a trial and error procedure is needed to find the right solution to a new problem. Errors related to the rules come from an inappropriate application of a pre-established rule for action to the situation: either the individual applies the right rule in the wrong way or fails to apply it, or he applies the wrong rule.

Individuals do not perform acts in isolation, however, but rather in a regulated social environment. Thus, while errors concern individual cognitive processes, violations are produced in a social context in which behavior is governed by procedures, practices, rules and norms (Reason et al., 1990). Violations are defined as deliberate deviations from practices, whether formalized or not, that are socially considered as "necessary to maintain the safe operation of a potentially hazardous system" (Reason et al, 1990, 1316). If the deviation is not intentional, the action will be classified as an error; if the difference between the action and socially constructed practices is voluntary, the action will be classified as a violation. Violations produced on the road mainly concern deviation from social rules that have a certain degree of intentionality, but their objective is not to cause injury or damages. These violations are associated with attitudes and motivations (Aberg, 1998; Yagil, 1998) and are influenced by the social context (Reason et al., 1990b).

This distinction between violations, errors and lapses was examined in several studies on drivers, using the Driver Behavior Questionnaire (DBQ) (Reason et al., 1990b). They showed that men and young drivers committed more violations than women, who committed more errors (Özkan et al., 2006; Reason et al., 1990b), that elderly drivers committed fewer violations but more errors (Gabaude et al., 2010) and that lapses increased with age (Özkan et al., 2006). New dimensions of accident risk behaviors have been developed in the context of 
the DBQ to measure drivers' aggressive behaviors (Lawton et al., 1997) and drivers' positive behaviors (Özkan and Lajunen, 2005) toward other road users.

The DBQ has been validated in many countries (Gras et al., 2006; Sullman et al., 2002; Xie and Parker, 2002) and was also used as a conceptual framework to construct tools for investigating these different types of behavior in other types of road users. Thus, Elliott, Baughan and Sexton (2007) developed a Motorcycle Rider Behavior Questionnaire (MRBQ) with 43 items. Submitted to a sample of more than 8,000 motorcyclists, it has shown that errors were the main predictor of accident risks for powered two-wheelers.

Based on the conceptual framework of the Driver Behavior Questionnaire (DBQ), Moyano Diaz (1997) validated a 16-item Pedestrian Behavior Questionnaire (PBQ) in Chile. Using the PBQ with Chilean pedestrians, he found results similar to those obtained with drivers: men and young pedestrians committed more violations than women and adult pedestrians (Moyano Diaz, 1997; 2002). This tool was recently validated in Brazil (Torquato and Bianchi, 2010) and a version was developed in Turkey, this time differentiating between violations, aggressive behaviors and errors (Yildirim, 2007). In both cases, the results showed more violations by men. Furthermore, more errors were observed among young pedestrians (17-25 years) than among older pedestrians (25-49 years) (Torquato \& Bianchi, 2010).

For now, this tool has never been validated in Western societies, even though it would be a useful resource for gaining a more detailed understanding of risky behaviors among pedestrians of all ages, studying the relationships between these different types of risky behaviors and pedestrian accidentology and analyzing risk factors. The purpose of this study was to validate a pedestrian behavior scale for all ages to differentiate between violations, errors and lapses among these behaviors. Based on the studies by Lawton et al. (1997) and Özkan and Lajunen (2005) on drivers and Yildirim (2007) on pedestrians, the goal of this tool 
was also to provide an understanding of aggressive and positive behaviors by pedestrians toward other road users.

\section{Method}

\subsection{Materials}

Using the conceptual framework of the DBQ (Reason et al., 1990b) and scales of aggressive driver behaviors (Lawton et al., 1997) and positive driver behaviors (Özkan and Lajunen, 2005) toward other road users, a Pedestrian Behavior Scale (PBS) was constructed. Its items were based on existing validated versions of the PBQ (Moyano Diaz, 1997; Torquato and Bianchi, 2010; Yildirim, 2007), as well as other self-reported pedestrian behavior scales (Elliott and Baughan, 2004; Granié, 2008). The items in the Likert scale differentiated between 5 types of pedestrian behaviors. Offences were defined as an intentional deviation from the legal rules of pedestrian behavior (10 items, e.g. "I cross outside the pedestrian crossing even if there is one less than 50 meters away"). Errors were defined as making decisions that put the pedestrian in danger, but without disobeying the legal rules (11 items, e.g. "I start walking across the street, but I have to run the rest of the way to avoid oncoming vehicles"). Lapses were defined as ill-suited behaviors related to a lack of concentration on the task (8 items, e.g. "I realize that I do not remember the route I have just taken"). According to this definition, crossing without looking was considered as a lapse behavior even when pedestrian light is green, particularly at a crossroad. Then, items concerning lapse during crossing (e.g. "I forget to look before crossing") did not precise if the crossing is regulated or not. Positive behaviors were defined as behaviors that appease social interactions (5 items, e.g. "I thank a driver who stops to let me cross"). Aggressive or antisocial behaviors were defined as conflicting behaviors with other road users (6 items, e.g. "I get angry with a driver and hit his vehicle"). In keeping with Torquato and Bianchi (2010), “filter" items were 
added (7 items, e.g. "I walk in covered areas (such as shopping centers)"). For each item, the participant was asked: “As a pedestrian, how often do you have the following behaviors?" from " $1=$ never" to " 6 = very often".

Along with answering the PBS, information was gathered on gender, age, the number of years participants have had a driver's license, ownership and use of a motor vehicle, kilometers driven weekly in a motor vehicle, weekly frequency of walking and daily walking time, and the accident history as a driver and as a pedestrian in the previous 5 years.

In order to obtain the widest, most diversified sample possible in terms of age, socioprofessional categories and geographical location, we undertook a web-based collection using social networks. The questionnaire was filled out online and its completion took 10 minutes. Only results from participants living in France were kept. The participants answered the questionnaire individually, after obtaining their informed consent. The responses were totally anonymous, as the individuals were only identified by the day and time of completion of the questionnaire.

\subsection{Participants}

The sample comprised 343 participants (126 men and 217 women) between 15 and 78 years of age $(M=33.86)$. The participants were separated into 5 age groups (table 1$)$. The distribution of participants of either gender was equivalent within each age group (Khi2(4)= $5.58, \mathrm{~ns})$

Most of the participants are managerial-level employees (38.8\%), students (26.8\%) or salaried employees (18.8\%). The majority of the participants have a driver's license $(81.6 \%)$ and a motor vehicle (63.8\%). They have had their licenses for 15.27 years on average. 
Most of the participants walk every day (54.6\%). The majority of the individuals walk between 15 and 30 minutes a day (40.2\%). 34.4\% of the individuals never drive, $23.9 \%$ of the participants drive every day and $23.3 \%$ cover between 50 and 150 kilometers a week. $81 \%$ of the sample declared that they had not had an accident in the previous 5 years.

\section{Results}

Means, standard deviations and distribution of responses to each of the 47 items in the PBS, ranked in descending order by mean value are presented in table 2 . Other than 4 filter items, the most frequently reported behavior concerned a behavior of positive interaction with an automobile driver (thanking a driver who yields his right-of-way), then behaviors categorized as errors and offences concerning the place and direction of crossing (crossing diagonally or ending the crossing diagonally, crossing between stopped or parked vehicles). Thus, the most commonly reported behaviors were not the most desirables from a safety point of view and concerned problematic behaviors in terms of visibility as well as behaviors violating traffic rules. Many of the behaviors that were less frequently reported concerned lapses and aggressive behaviors toward other road users. Forgetting to look or being aggressive to others, behaviors that showed a lack of control of the situation or of oneself, were not common, or, in any case, were not frequently reported in the study sample. Although these behaviors did not often appear, the analysis of the distribution of responses in table 2 showed that a significant share of the sample reported having this type of behavior.

\subsection{Tool validation}

In order to explore the PBS's factorial structure, principal component analysis with orthogonal Varimax rotation was carried out on all 40 items in the scale, excluding the 7 filter 
items. The scree plot indicated that the data best fit a four-factor solution, which accounted for $39.82 \%$ of the total variance. The Kaiser-Meyer-Olkin measure of sampling adequacy was satisfactory (0.86), Bartlett's test of sphericity was significant (0.0001) and the determinant of the matrix was close to zero (5.82E-007). Four axes with eigenvalues $>1$ were identified. A cut-off point of .40 was used for item loading values.

The first axis, "transgression", explained $21.09 \%$ of the variance. It was defined by 15 items relative to offences ( 7 items) and errors ( 8 items) while crossing or travelling. Two offence items (item 20 and item 30), loading both on this axis and on the second axis, were excluded from the final scale. The items loading on this axis all had in common the intentional nature of the dangerous behavior, whether a deliberate offence contrary to the legal rules (e.g. "I cross the street even though the pedestrian light is red", factor loading: .77) or an erroneous or careless decision concerning the place or time of crossing, without an offence contrary to the legal rules (e.g. "I cross the street between parked cars", factor loading: .74). According to the classification of aberrant behaviors drawn up by Reason et al. (1990), behaviors loading on axis 1 referred both to errors and violations.

The second axis, "lapses" explained $7.73 \%$ of the variance and was determined by 7 items related to inattention. One item relative to errors (item 10) and one item relative to inattention but also loading on axis 4 (item 41) were excluded from the final scale. All items loading on this axis were characterized by the unintentional character of the dangerous behavior and by the omission of part of the task to be performed, either by distraction (e.g. "I forget to look before crossing because I am thinking about something else" - factor loading: .79), or by focusing on a competing task or a situation external to the task (e.g. "I forget to look before crossing because I want to join someone on the sidewalk on the other side" - factor loading: .74). In the classification by Reason et al. (1990), these behaviors referred to lapses. 
The third axis, "aggressive behaviors", explaining $6.17 \%$ of the variance, was determined by 5 items of aggressive behaviors toward other road users. The items on this axis concerned the expression of negative emotions leading to aggressive interaction with different types of road users (e.g. "I get angry with another user and insult him", factor loading: .76) or specifically toward drivers (e.g. "I get angry with a driver and hit his vehicle", factor loading: .57).

The fourth axis, "positive behaviors", explaining $4.84 \%$ of the variance, comprised 5 positive behavior items aimed at facilitating interactions with other road users, whether drivers (e.g. "I let a car go by, even if I have the right-of-way, if there is no other vehicle behind it", factor loading $=.61$ ) or other pedestrians (e.g. "I stop to let the pedestrians I meet by", factor loading $=.49$ ). After eliminating the 8 problematic items and another PCA with Varimax rotation, the 32 items comprised 4 axes that explained $43.83 \%$ of the variance. All the results are presented in table 3.

The mean scores for items of transgression, lapse, aggressive and positive behaviors were calculated and used as composite scales in the following analyses. Cronbach's alphas, calculated for transgression (.89), lapses (.83), aggressive behavior (.70) and positive behavior (.53) items indicated that the scales had acceptable internal reliability, except for the positive behavior scale.

Furthermore, for the transgression axis, two sub-scores were calculated to observe the effect of demographic and mobility variables on the two dimensions of this score: items concerning offences against the legal rules and error items. Here again, the alphas showed acceptable internal reliability ( $\alpha=.84$ and $\alpha=.79$ for offence scale and error scale respectively).

\subsection{Refining the scale}


The main objective of the study was to develop a reliable self-reporting instrument for measuring pedestrians' risky behaviors. The 32-item version may not be practical for use in future self-reporting studies because, when used with other self-reporting measures, it can lead to questionnaires that are too long in terms of completion time. A shorter version that is capable of reliably measuring the factor structure reported above would be more practical to use. For this, the 4 items in each of the 5 dimensions involved (offences, errors, lapses, aggressive behaviors and positive behaviors) with the highest score for each of the 4 factors were selected, and these 20 items (added to 3 filter items, see the appendix) underwent another PCA with Varimax rotation. The results showed that the items related to transgressions (errors and offences) all loaded on the first factor, that lapse items all loaded on the second factor, aggressive behavior and positive behavior items loaded on the third and fourth factors, respectively. After rotation, the four factors explained $55.07 \%$ of the variance. Factorial analyses on the 20 items of the PBS were also performed for each gender and age group (15-25 years, 25-35 years, and over 35, in order to obtain groups of comparable sizes). Given the succinctness of the results, the analyses are not presented here. It should be pointed out, however, that in each analysis performed for each gender and age group, the transgression items only loaded on one factor (i.e. had scores $<.40$ on the other factors), that lapse items only loaded on a second factor, and aggressive and positive behaviors only loaded on a third and fourth factor, respectively. Thus, the factorial structure found for the total sample was robust; independent of age and gender, the 4 -factor solution was a suitable model. The long version of the pedestrian behavior scale, with 32 items, was used for the rest of the analysis.

\subsection{Inter-score relations}


Considering the potential effects of age and gender on certain scales, partial correlations between the different dimensions of the PBS were performed, while checking the effects of age and gender (table 4).

The correlation matrix showed positive correlations between transgression, lapses and aggression: the more transgressions individuals declared, the more they also declared lapses and aggressive behaviors. Positive behaviors were negatively correlated with lapses: the more individuals declared positive behaviors toward other road users, the less they declared lapses as pedestrians.

\subsection{Effects of demographic variables}

ANOVAs were carried out on the effects of gender (2) and age (5) on all the composite scores in the pedestrian behavior scale: transgressions, lapses, aggressive behaviors and positive behaviors, as well as on the two offence and error sub-scores. The means and standard deviations were presented in table 5 .

ANOVA showed an underlying trend toward a difference between men and women $(\mathrm{F}(1.333)=3.29, \mathrm{p}=.07$, partial eta squared $=.01)$ and a significant age effect $(\mathrm{F}(4.333)=9.76$, $\mathrm{p}<.0005$, partial eta squared $=.105)$ on the transgression score. Men tended to declare more transgressions than women and the Bonferroni post-hoc tests showed that those under the age of 35 declared significantly more transgressions than those over $45(\mathrm{p}<.05)$. There was no interaction between gender and age on the transgression score $(\mathrm{F}<1)$.

A significant difference was observed between men and women $(\mathrm{F}(1.333)=4.33, \mathrm{p}<.05$, partial eta squared $=.013)$ as was a significant age effect $(\mathrm{F}(4.333)=9.44, \mathrm{p}<.0005$, partial eta squared $=.102)$ on the offence score. Men declared more offences against the legal rules than women and the Bonferroni post-hoc tests showed that those under the age of 35 declared 
significantly more offences than those over $45(\mathrm{p}<.05)$. There was no interaction between gender and age on the offence score $(\mathrm{F}<1)$.

A significant age effect was observed on the error score $(F(1.333)=7.95, p<.005$, partial eta squared $=.087)$. The Bonferroni post-hoc tests showed that those under the age of 35 declared significantly more errors than those over $45(\mathrm{p}<.05)$. There was no gender effect $(\mathrm{F}(1.333)=1.58, \mathrm{~ns})$, nor any interaction between gender and age on the error score $(\mathrm{F}<1)$. A significant difference was observed between men and women $(F(1.333)=3.90, p<.05$, partial eta squared $=.012)$ as was a significant age effect $(\mathrm{F}(4.333)=2.69, \mathrm{p}<.05$, partial eta squared $=.031)$ on the positive behavior score. Men declared fewer positive behaviors than women and those between 36-45 years of age declared more positive behaviors than other age groups $(\mathrm{p}<.05)$. There was no interaction between gender and age on the positive behavior score $(\mathrm{F}(4.332)=1.14, \mathrm{~ns})$.

No significant gender effect was observed $(F(1.333)=2.63$, ns), nor age effect $(F(4.333)=1.73$, $\mathrm{ns})$ nor interaction between gender and age $(\mathrm{F}<1)$ on the lapses score. No significant gender effect was observed $(\mathrm{F}<1)$, nor age effect $(\mathrm{F}(4.333)=1.58$, ns) nor interaction between gender and age $(\mathrm{F}<1)$ on the aggressive behavior score.

\subsection{Effects of variables concerning mobility}

Means were compared using Student's $t$ distribution to measure the effect of the following variables: having a driver's license, motor vehicle ownership and involvement in an accident in the previous 5 years.

The results showed that individuals who did not have a license declared significantly more positive behaviors than individuals who did have a driver's license $(\mathrm{M}=20.95, \mathrm{SD}=4.36$ and 
$\mathrm{M}=19.48, \mathrm{SD}=4.05$, respectively) $(\mathrm{t}(342)=2.40, \mathrm{p}<.05)$. The "having a driver's license" variable did not have any effect on the other scores.

Furthermore, compared with individuals who owned a motor vehicle, individuals who did not own a motor vehicle declared significantly more errors $(\mathrm{t}(341)=3.14, \mathrm{p}<.005)(\mathrm{M}=20.06$, $\mathrm{SD}=5.91$ and $\mathrm{M}=22.09, \mathrm{SD}=5.48$, for individuals with and without a driving license, respectively) and more lapses $(\mathrm{t}(341)=2.96, \mathrm{p}<.005)(\mathrm{M}=11.90, \mathrm{SD}=6.44$ and $\mathrm{M}=13.48$, $\mathrm{SD}=4.88$, for individuals with and without a license, respectively). The "owning a motor vehicle" variable had no effect on the other scores.

The individuals who had been involved in a traffic accident in the previous 5 years declared significantly fewer lapses than the others $(\mathrm{t}(341)=2.19, \mathrm{p}<.05)(\mathrm{M}=11.31, \mathrm{SD}=3.58$ and $\mathrm{M}=12.74, \mathrm{SD}=4.99$, for individuals who had had or had not had an accident in the previous 5 years, respectively). The "accident in the previous 5 years" variable did not have any effect on the other scores.

ANOVAs were carried out to measure the effect of driving frequency, kilometers driven weekly, walking frequency and daily walking time on the scores on the pedestrian behavior scale.

Driving frequency had a primary effect on the number of error behaviors as a pedestrian $(\mathrm{F}(5.337)=2.40, \mathrm{p}<.05$, partial eta squared $=.034)$. The post-hoc tests showed that individuals who drove 4 times a week declared significantly fewer error than individuals who never drove $(p<.05)$. Driving frequency had an effect on lapses $(F(5.337)=2.70, p<.05$, partial eta squared=.039). The Bonferroni post-hoc tests showed that individuals who drove 1 to 4 times a week declared more lapses as pedestrians than individuals who drove 5 times a week. The results did not show any effect of driving frequency on offences $(F(5.337)=1.06, \mathrm{~ns})$, transgressions $(\mathrm{F}(5.337)=1.60, \mathrm{~ns})$, aggressions $(\mathrm{F}<1)$ or positive behaviors $(\mathrm{F}<1)$. 
A primary effect for kilometers driven weekly was observed on lapses $(F(5.337)=2,64, p<.05$, eta $=0.38$ ). The Bonferroni post-hoc tests showed that individuals who drove between 250 and $350 \mathrm{~km}$ a week declared significantly fewer lapses than individuals who drove fewer than 50 $\mathrm{km}$ a week. These was no significant effect of kilometers driven weekly on errors $(\mathrm{F}(5.337)=1.002, \mathrm{~ns})$, offences $(\mathrm{F}<1)$, transgressions $(\mathrm{F}<1)$, aggressive behaviors $(\mathrm{F}<1)$ or positive behaviors $(\mathrm{F}<1)$.

Walking frequency had a primary effect on lapses $(\mathrm{F}(5.337)=2.64, \mathrm{p}<.05$, eta $=.038)$. The Bonferroni post-hoc tests showed that declared lapses increased with walking frequency. A primary effect was also observed for walking frequency on transgressions $(\mathrm{F}(5.337)=4.86$, $\mathrm{p}<.0005$, eta $=.067)$, offences $(\mathrm{F}(5.337)=4.25, \mathrm{p}<.001$, eta $=.059)$ and errors $(\mathrm{F}(5.337)=4.84$, $\mathrm{p}<.0005$, eta $=.067)$. The post-hoc tests showed that individuals who walked 3 times a week declared significantly fewer transgressions, fewer offences and fewer errors than individuals who declared that they walked daily. There was no walking frequency effect on aggressive behaviors $(\mathrm{F}(5.337)=1.34, \mathrm{~ns})$ and positive behaviors $(\mathrm{F}<1)$.

Daily walking time did not have an effect on transgressions $(\mathrm{F}(5.337)=1.78$, ns), offences $(\mathrm{F}(5.337)=1.75, \mathrm{~ns})$, errors $(\mathrm{F}(5.337)=1.66, \mathrm{~ns})$, lapses $(\mathrm{F}(5.337)=1.08, \mathrm{~ns})$, aggressive behaviors $(\mathrm{F}(5.337)=1.47, \mathrm{~ns})$ or positive behaviors $(\mathrm{F}(5.337)=1.40, \mathrm{~ns})$.

\subsection{Attitudes toward walking}

Certain filter items in the pedestrian behavior scale provided an indication of whether walking was a constraint (item 19 "I walk because I have no other choice") or a choice (item 7 "I walk for the pleasure of it"). The scores for these two items were negatively correlated $(r=-.28, n=$ $343, \mathrm{p}<.0005)$. The score for the "forced walking" item did not vary in relation to walking frequency $(\mathrm{F}(5.312)=1.81, \mathrm{~ns})$ nor of weekly walking time $(\mathrm{F}<1)$. The score for the "pleasure 
walking" item varied in relation to walking frequency $(F(5.312)=5.14, p<.0005)$ but did not vary in relation to weekly walking time $(\mathrm{F}<1)$. The Bonferroni post-hoc tests showed that the participants who declared that they walked fewer than 2 times a week declared significantly less pleasure walking than the participants who walked more than 2 times a week.

For the rest of the analyses, the scores for the "forced walking" (item 19) and "pleasure walking" (item 7) items were recoded into two terms: low score (1 to 3 ) and high score (4 to 6). Means were compared using Student's t distribution to measure the effect of the forced walking and pleasure walking scores on the pedestrian behavior scale scores.

The "forced walking" score had a significant effect on the transgression score $(\mathrm{t}(341)=-2.01$, $\mathrm{p}<.05)$, and more particularly on the error score $(\mathrm{t}(341)=-2.24, \mathrm{p}<.05)$. Compared with those individuals who declared that they were rarely forced to walk, the individuals who declared that they were often forced to walk committed more transgressions $(\mathrm{M}=41.36, \mathrm{SD}=12.24$ and $\mathrm{M}=44.08, \mathrm{SD}=11.47$ for low and high forced walking scores, respectively), and more errors $(\mathrm{M}=20.27, \mathrm{SD}=5.90$ and $\mathrm{M}=21.74, \mathrm{SD}=5.60$ for low and high forced walking scores, respectively).

For "pleasure walking", the results showed a significant effect of the response to item 7 (pleasure walking) on the error score $(\mathrm{t}(341)=-2.54, \mathrm{p}<.01)$, on the lapses score $(\mathrm{t}(341)=-2.83$, $\mathrm{p}<.005)$ and on the positive behavior score $(\mathrm{t}(341)=-2.66, \mathrm{p}<.01)$. Compared with those individuals who declared that they rarely walked for pleasure, the individuals who declared that they often walked for pleasure committed more errors $(\mathrm{M}=19.77, \mathrm{SD}=5.36$ and $\mathrm{M}=21.41$, $\mathrm{SD}=6.01$ for low and high pleasure walking scores, respectively), more lapses $(\mathrm{M}=11.53$, $\mathrm{SD}=3.77$ and $\mathrm{M}=13.03, \mathrm{SD}=5.23$ for low and high pleasure walking scores, respectively) and had more positive behaviors $(M=19.07, S D=3.93$ and $M=20.29, S D=4.21$ for low and high pleasure walking scores, respectively). 


\section{General discussion}

\subsection{Constructing a research tool}

The objective of this study was to develop and validate a self-reported behavior scale for pedestrians of all ages that can differentiate between offences, errors and lapses among injury risk behaviors, as well as to measure aggressive and positive behaviors by pedestrians toward other road users.

The validation study was carried out on a heterogeneous sample in terms of age and sociocultural origin. It provided a differentiation between the behaviors proposed on the scaletransgressions, lapses, positive and aggressive behaviors. However, a lack of differentiation between offences and errors was observed.

A reliable scale of self-reported behaviors providing a useful classification of pedestrian behaviors at all ages was developed in this study. A 20 -item instrument was produced from the initial 40 items relative to specific examples of pedestrian behaviors, most of them with accident risks. The short version of the tool produced a structure with 4 factors that was easy to interpret, as the items in each factor - transgressions, lapses, aggressive behaviors and positive behaviors - had good internal reliability, except for positive behaviors. Furthermore, the analyses carried out separately on men and women as well as on the 3 age groups between 15 and 75 showed that, independent of age and gender, the factorial solution with 4 factors in the Pedestrian Behaviors Scale was robust. These results reproduced among pedestrian from 15 to 75 years of age those of similar of research published previously on adolescents (Elliott and Baughan, 2004; Sullman et al., 2011; Sullman and Mann, 2009), demonstrating a level of repeatability and applicability across various nations and various age groups. Furthermore, this tool also added two new dimensions of pedestrian behaviors - aggressive and positive 
behaviors - that can be beneficial for research investigating pedestrian behaviors and psychological mechanisms which can explain those behaviors.

Not surprisingly, the pedestrian behavior classification produced by the PBS in this study is not completely in line with the aberrant behavior classification produced by Reason et al. (1990) for driver behaviors. These differences probably reflect the differences between the two road user populations that these two questionnaires are used to study.

Despite these differences, there are a few concordant points between this study and the studies using the DBQ structure on different groups of motorized road users. Both in the DBQ classification by Reason et al. (1990) and in the PBS constructed here, lapses - acts of omission putting the individual in a situation of personal endangerment but with no intent to take a risk - was clearly differentiated from intentional transgressions against the legal rules or rules of caution.

The main difference between the factorial structure of the DBQ and that produced by the PBS is that, in the present study, the transgression axis (axis 1) contains items that can be classified as offences and items referring to errors. As far as we know, neither Torquato (2010) nor Moyano Diaz (1997) performed factorization on their versions of the PBQ among adults and Yildirim's version (2007) did not differentiate between errors and lapses. This result is consistent, however, with the study by Elliott and Baughan (2004) on the pedestrian behavior scale for adolescents, ARBQ, where factor 1, "unsafe road crossing", comprised both error and transgression behaviors, some transgression items also being found on axis 2 , "dangerous playing in the road". Thus, the lack of distinction between errors and transgression could be observed both in the study by Elliott and Baughan (2004) among adolescents and in the current study among pedestrians of all ages and seems to reflect differences between pedestrians' and drivers' behaviors. 
Errors and offences against the legal rules by pedestrians are therefore committed by the same individuals, while they are differentiated among drivers (Lawton et al., 1997; Reason et al., 1990a). Furthermore, the behaviors comprising axis 1 have in common the fact that their underlying objective is to maintain speed and to shorten walking distance, both factors that explain lack of rule compliance among pedestrians (Sisiopiku and Akin, 2003). One explanation may be that individuals usually do not differentiate between legal rules (crossing light, pedestrian crossing) and rules of caution (avoiding views obstructed by stopped or parked vehicles, for example) and think that their transgressions are of the same type and have the same level of consequences. Analyses of response frequencies tend to show that these injury risk behaviors are widespread among pedestrians and that not only do legal rules not have any more effect on pedestrians than rules of caution, but also, more generally, social norms tend to lead them not to take such rules into account and to transgress all such norms. For all these items, it would be interesting to measure normative beliefs (Granié, 2008) and the internalization of rules (Granié, 2009) to understand if formal and informal rules are differentiated by pedestrians and, more generally, to observe how representations of rules relative to pedestrian behavior develop between childhood and adulthood.

Given that the error-lapses-violation classification was not completely found in this study, a theoretical approach that takes these results into account needs to be identified in order to understand the psychological mechanisms underlying pedestrian behaviors. To understand the results, a sharp distinction can be made as to whether dangerous behavior is intentional or not. Thus, in the current study, transgressions against formal and informal rules are distinguished from lapses by their intentional nature. The same distinction based on the intentionality of the behavior mentioned among the pedestrian self-reported injury risk behaviors was suggested by Granié (2008) where a distinction was found between self-endangerment behaviors (lapses) and behaviors with intentional risk-taking in each of the sub-scales, whether 
concerning self-reported behaviors, perception of danger or risk for oneself or normative beliefs. These intentional dangerous behaviors can be considered as risk-taking, defined as deliberately undertaking a behavior for which the accident risk is perceived (Saad, 1988) or as any voluntary behavior for which the uncertainty surrounding the consequences for oneself or others is perceived (Trimpop, 1994). Although this needs to be confirmed by future studies, it could be that the level of risk-taking in offences against the legal rules and in errors are considered to be weak by our sample because the level of uncertainty is considered by pedestrians to be low in both cases. The level of uncertainty could be perceived as low because the social norm is to transgress - as shown by the mean frequencies with which these behaviors are declared by our sample -, or because the danger of these transgressive behaviors is not well perceived. The high frequency of transgressions and the low relative frequency of pedestrian accidents no doubt reduce the perception of risk related to these behaviors. Research is needed to explore this line of explanation.

Furthermore, while offences and errors form a single transgression axis, the potentially explanatory variables have a differentiated effect on the two sub-scores. Thus, gender differences were observed for offences against legal rules, but not for errors, driving frequency and attitudes toward walking affected error score but not offence score. This could signify the psychological mechanisms explaining offences and errors and then the modes of remediation are not the same (Reason et al., 1990a) even these two types of behaviors are not differentiated by pedestrian. Therefore, it would be useful, as it was made in the current study of the effect of demographic and mobility variables, to differentiate between offences against the legal rules and error behaviors in transgressions.

4.2. Results for the effects of demographic and mobility variables

\subsubsection{Gender and age}


The results show that men commit more offences against the legal rules than women. There is no difference, however, between men and women for the error score. The highest offence score among the male pedestrians in the sample confirms the results observed in other studies, both for the behaviors declared (Moyano Diaz, 2002) and for behaviors observed (Latrémouille et al., 2004; Tom and Granié, 2011). More generally, the difference between genders for offences is well known in studies on driver behavior (Harré et al., 1996; Simon and Corbett, 1996) and demonstrates a different relationship to the legal rules among male and female pedestrians. This difference has already been shown for observed pedestrian behaviors (Tom and Granié, 2011), with men complying less with pedestrian crossing lights than women, but complying with the spatial rules of pedestrian crossing as much as women do. The results also show that women have more positive behaviors toward other road users. This result can be understood in relation to stereotypes defining women's role in our societies (Granié, 2009): feminine stereotypes encourage mutual assistance and caring for others, while masculine stereotypes encourage competition and domination.

The results show that age has an effect on several of the dimensions measured here. Individuals under the age of 35 are in opposition to those over 45 , committing more offences and more errors. Furthermore, 35-45 year-olds have more positive behaviors than individuals in other age groups. It is known that walking frequency varies with age - younger people and older people walk the most (de Solère and Papon, 2010) - but this does not explain why younger people declare having more aberrant behaviors than older people. Risk-taking behaviors during adolescence are well known and have been interpreted as a method of developing optimal social and psychological competence, autonomy, independence, and selfregulation (Baumrind, 1991; Parsons et al., 1997; Silbereisen and Noack, 1988). Research now shows that curvilinear relation between age and risk-taking from childhood to adulthood is linked to changes in the brain's socio-emotional and cognitive control systems. The first 
system increases reward-seeking after childhood, whereas the second system improves capacity for self-regulation after adolescence (Steinberg, 2008). The increase in positive behaviors at 35-45 years of age, followed by the decrease in aberrant behaviors after the age of 45, may suggest that, after a greater tendency toward risky behavior among younger people, there is increasing awareness of sharing spaces, leading to greater behavioral control in older people. Change with age in the reasons for walking has also to be taken into account (shopping rather than going to school and later to work) and walking can become a question of choice rather than constraint from the age of 35 . These explanations obviously need to be confirmed through more studies on mobility and attitudes toward walking in relation to age, and their effects on pedestrian behaviors.

\subsubsection{Mobility and attitudes toward walking}

The results show an effect of the type of mobility on pedestrian behavior scale scores. Thus, individuals without a vehicle declare more errors and lapses, individuals who never drive declare more errors, and individuals who rarely drive or drive short distances declare more lapses. Likewise, individuals who walk regularly declare more offences and errors. The first explanation for these results comes from the greater opportunity to demonstrate aberrant behaviors when there is a greater walking frequency. The more frequently one walks and the longer the distances, the more one risks committing errors, being inattentive or breaking traffic regulations. Another line of explanation may be the effect of driving experience on behaviors as a pedestrian. Thus, in keeping with Holland and Hill (2010), who found that driving experience has an effect on crossing by elderly pedestrians, it is possible that there is a cross-over of skills from driving to pedestrian behaviors, or at least a greater awareness of interactions with drivers and risk, leading to behaviors that are less risky when crossing. 
Furthermore, we can see that it is walking frequency, and not walking time, that leads to more risky behaviors when crossing.

\subsubsection{The effect of attitudes toward walking on pedestrian behaviors}

The results also show an effect of attitudes toward walking on the pedestrian behavior scale scores. Being forced to walk or walking for the pleasure of it leads to more errors.

Furthermore, individuals who declare that they walk for pleasure also declare more lapses and more positive behaviors. Moreover, pleasure walking is not related to walking time, but rather to walking frequency. Individuals who walk frequently declare walking for the pleasure of it more and commit more errors and lapses, but at the same time have more positive interactions with other road users.

The effects of whether walking is forced or chosen have already been shown for perception of the environment, in terms of safety and security (Miaux, 2008). It has also been shown that individuals who choose to walk are more sensitive to friendly interactions and seek to establish a privileged relationship with the urban environment, while people who have no choice in their mode of transportation - walking being more common in the weakest and most vulnerable socio-demographic groups (de Solère and Papon, 2010) - have a perception that the urban environment is more unsafe and are more sensitive to security elements than to safety elements (Miaux, 2008). Results of the current study may be explained by a different way of occupying urban spaces: forced pedestrians commit more errors because they have more anxiety in the urban space, avoid interactions with others, focus on the objective of their trip and take the shortest route (between parked or stopped vehicles). On the other hand, pedestrians who enjoy walking may feel more comfortable with the urban space, takes time to stroll, consider that their territory is not limited to sidewalks and pedestrian crossings and more easily accept interactions with other road users. These results obviously need to be 
confirmed, but they appear to point to an impact of attitudes toward walking - experienced as a constraint or chosen - on risk behaviors among pedestrians.

\section{Conclusion}

The results of this study do not correspond to the traditional classification of aberrant behaviors by Reason et al. (1990) dividing them into errors, lapses and violation, but do provide a differentiation of pedestrian behaviors in terms of transgressions, lapses, aggressive and positive behaviors. They provide an easy-to-interpret categorization of pedestrian behaviors with accident risks, and the Pedestrian Behavior Scale can be useful to all researchers investigating pedestrian safety, whatever the age.

As in the DBQ by Reason et al. (1990) and the ARBQ by Elliott and Baughan (2004), classification of behaviors provided by the PBS is based on declared behaviors and not on observed behaviors. Observing behavior is important to take into account and study the huge effect of environment on pedestrian behaviors that cannot be understand through self-reported questionnaire (Havard and Willis, 2012; Sisiopiku and Akin, 2003). Thus, self-report studies are not sufficient to observe the effect of more recent road designs, such as shared spaces, which interactions between pedestrians and slow traffic would not be viewed as an unsafe situation but rather as an evidence of a well-designed multi-use space (Kaparias et al., 2012). Self-reporting measurements are, however, widely recognized as valid measurements in the social sciences (Corbett, 2001). This is notably the case when studying injury risk behaviors, which are hard to measure through located observational studies or when studying psychological factors that can explain pedestrian behaviors. Furthermore, for many social behaviors, research has shown that relatively strong associations are found between declared behaviors and more objective behavioral measurements (West et al., 1993). Therefore, observations and self-reported questionnaires on pedestrian behaviors should be conceived as 
complementary approaches to explore and understand the multiple factors which intervene in a complex phenomenon: the interaction between the pedestrian and his/her road environment in a complex task which brings psychomotor skills, cognitive and motivational process into play (Saad, 1988).

Behaviors as measured by the PBS can be a good approach to injury-risk behaviors measured more objectively. The PBS can be used to differentiate between transgressions, lapses, aggressive and positive behaviors. This ability to measure positive and aggressive behaviors, along with aberrant pedestrian behaviors, will provide a more detailed understanding of pedestrian behaviors as well as of related psychological and mobility factors. Validated on a French population, this instrument may prove to be useful in measuring and analyzing differences in the frequency of these different types of behavior, notably in pedestrian populations that are most at risk - i.e. adolescents and elderly -, to understand changes with age in pedestrian behaviors and associated factors and thus to be able to better adapt preventive actions to the different populations of vulnerable road users.

\section{References}

Aberg, L., 1998. Traffic rules and traffic safety. Safety Science 29, 205-215.

Abou, A., Granié, M.A., Mallet, P., 2008. Recherche de sensations, attachement aux parents et prise de risque dans l'espace routier chez l'adolescent piéton. In: Granié, M.A., Auberlet, J.-M. eds. Le piéton et son environnement: quelles interactions? Quelles adaptations? Actes n¹15. Les collections de l'INRETS, Arcueil, pp. 121-133.

Baumrind, D., 1991. The influence of parenting style on adolescent competence and substance use. Journal of Early Adolescence 11 (1), 56-95.

Corbett, C., 2001. Explanations for "understating"' in self-reported speeding behaviour. Transportation Research Part F: Traffic Psychology and Behaviour 4, 133-150. 
de Solère, R., Papon, F., 2010. La mobilité à pied: que nous apprennent les dernières enquêtes? In: Granié, M.A., Auberlet, J.M. eds. Le piéton: nouvelles connaissances, nouvelles pratique et besoins de recherche. Les Collections de l'INRETS, Bron, pp. $15-24$.

Elliott, M.A., Baughan, C.J., 2004. Developing a self-report method for investigating adolescent road user behavior. Transportation Research Part F: Traffic Psychology and Behaviour 7 (6), 373-393.

Elliott, M.A., Baughan, C.J., Sexton, B.F., 2007. Errors and violations in relation to motorcylists' crash risk. Accident Analysis \& Prevention 39, 491-499.

Evans, D., Norman, P., 1998. Understanding pedestrians' road crossing decisions: an application of the theory of planned behaviour. Health Education Research: Theory and Practice 13 (4), 481-489.

Evans, D., Norman, P., 2003. Predicting adolescent pedestrians' road-crossing intentions: an application and extention of the Theory of Planned Behavior. Health Education Research: Theory and Practice 18 (3), 267-277.

Gabaude, C., Marquié, J.-C., Obriot-Claudel, F., 2010. Self-regulatory driving behaviour in the elderly: relationships with aberrant driving behaviours and perceived abilities. Le Travail Humain 73 (1), 31-52.

Granié, M.A., 2008. Influence de l'adhésion aux stéréotypes de sexe sur la perception des comportements piétons chez l'adulte. Recherche - Transports - Sécurité 101, 253-264.

Granié, M.A., 2009. Sex differences, effects of sex-stereotype conformity, age and internalization on risk-taking among pedestrian adolescents. Safety Science 47, 12771283. 
Gras, M.E., Sullman, M.J.M., Cunill, M., Planes, M., Aymerich, M., Font-Mayolas, S., 2006. Spanish drivers and their aberrant driving behaviours. Transportation Research Part F: Traffic Psychology and Behaviour 9 (2), 129-137.

Harré, N., Field, J., Kirkwood, B., 1996. Gender differences and areas of common concern in the driving behaviors and attitudes of adolescents. Journal of Safety Research 27 (3), 163-173.

Havard, C., Willis, A., 2012. Effects of installing a marked crosswalk on road crossing behaviour and perceptions of the environment. Transportation Research Part F: Traffic Psychology and Behaviour 15, 249-260.

Holland, C.A., Hill, R., 2010. Gender differences in factors predicting unsafe crossing decisions in adult pedestrians across the lifespan: A simulation study. Accident Analysis \& Prevention doi:10.1016/j.aap.2009.12.023.

Kaparias, I., Bell, M.G.H., Miri, A., Chan, C., Mount, B., 2012. Analysing the perceptions of pedestrians and drivers to shared space. Transportation Research Part F-Traffic Psychology and Behaviour 15 (3), 297-310.

Latrémouille, M.-E., Thouez, J.-P., Ranou, A., Bergeron, J., Bourbeau, R., Bussière, Y., 2004. Le sexe est-il une variable pertinente pour l'étude du comportement des piétons en intersection urbaine? [Is gender a relevant variable when studying the behaviors of pedestrians at urban intersections?]. Recherche - Transports - Sécurité 84, 171-188.

Lawton, R., Parker, D., Manstead, A.S.R., Stradling, S.G., 1997. The role of affect in predicting social behaviours: The case of road traffic violations. Journal of Applied Social Psychology 27, 1258-1276.

Miaux, S., 2008. Comment la façon d'envisager la marche conditionne la perception de l'environnement urbain et le choix des itinéraires piétonniers. L'expérience de la marche dans deux quartiers de Montréal. [How the way of considering walk 
conditions the perception of the urban environment and the choice of pedestrian routes. The experience of walk in two districts of Montréal]. Recherche - Transports Sécurité 101, 327352.

Moyano Diaz, E., 1997. Teoria del Comportamiento Planificado e intencion de infringir normas de transito en peatones [Théorie du Comportement Planifié et intention de transgresser les règles routières chez les piétons]. Estudos des Psicologia 2 (2), 335 348.

Moyano Diaz, E., 2002. Theory of planned behavior and pedestrians' intentions to violate traffic regulations. Transportation Research Part F: Traffic Psychology and Behaviour $5(3), 169-175$.

ONISR, 2007. La sécurité routière en France. Bilan de l'année 2006 La Documentation Française, Paris.

Özkan, T., Lajunen, T., 2005. A new addition to DBQ: Positive Driver Behaviours Scale. Transportation Research Part F: Traffic Psychology and Behaviour 8 (4-5), 355-368.

Özkan, T., Lajunen, T., Chliaoutakis, J., Parker, D., Summala, H., 2006. Cross-cultural differences in driving behaviours: a comparison of six countries. Transportation Research Part F: Traffic Psychology and Behaviour 9 (3), 227-242.

Parsons, J.T., Siegel, A.W., Cousins, J.H., 1997. Late adolescent risk-taking: effects of perceived benefits and perceived risks on behavioral intentions and behavioral change. Journal of Adolescence 20, 381-392.

Rasmussen, J., 1980. What can be learned from human errors report? In: Duncan, K., Gruneberg, M., Wallis, D. eds. Changes in Working Life. Wiley, London. Rasmussen, J., 1983. Skills, rules, knowledge; signals, signs, and symbols, and other distinctions in human performance models. IEEE Transactions on Systems, Man and Cybernetics 13, 257-266. 
Reason, J., Manstead, A., Stradling, S., Baxter, J., Campbell, K., 1990a. Errors and violations on the roads: a real distinction? Ergonomics 33 (10-11), 1315-1332.

Reason, J.T., 1987. Generic error modelling system (GEMS): a cognitive framework for locating common human error forms. In: Rasmussen, J., Duncan, K., Leplat, J. eds. New Technology and Human Error. Wiley, London, pp. 15-23.

Reason, J.T., Manstead, A.S.R., Stradling, S., Baxter, J.S., Campbell, K., 1990b. Errors and violations on the roads: a real distinction? Ergonomics 33 (10/11), 1315-1332.

Saad, F., 1988. Prise de risque ou non perception du danger. Recherche - Transports - Sécurité septembre (18-19), 55-62.

SafetyNet, 2009. Pedestrians \& Cyclists.

Silbereisen, R.K., Noack, P., 1988. On the constructive role of problem behavior in adolescence. In: Bolger, N. ed. Person and Context: developmental processes. Cambridge University Press, Cambridge.

Simon, F., Corbett, C., 1996. Road traffic offending, stress, age, and accident history among male and female drivers. Ergonomics 39, 757-780.

Sisiopiku, V.P., Akin, D., 2003. Pedestrian behaviors at and perceptions towards various pedestrian facilities: an examination based on observation and survey data. Transportation Research Part F: Traffic Psychology and Behaviour 6, 249-274.

Steinberg, L., 2008. A sociol neuroscience perspective on adolescent risk-taking. Developmental Review 28, 78-106.

Sullman, M.J.M., Gras, M.E., Font-Mayolas, S., Masferrer, L., Cunill, M., Planes, M., 2011. The pedestrian behaviour of Spanish adolescents. Journal of Adolescence 34 (3), 531539

Sullman, M.J.M., Mann, H.N., 2009. The road user behaviour of New Zealand adolescents. Transportation Research Part F: Traffic Psychology and Behaviour 12, 494-502. 
Sullman, M.J.M., Meadows, M.L., Pajo, K.B., 2002. Aberrant driving behaviours amongst New Zealand truck drivers. Transportation Research Part F: Traffic Psychology and Behaviour 5 (3), 217-232.

Tom, A., Granié, M.A., 2011. Gender Differences in Pedestrian Rule Compliance and Visual Search at Signalized and Unsignalized Crossroads. Accident Analysis \& Prevention $43(5), 1794-1801$.

Torquato, R.J., Bianchi, A.S.A., 2010. Comportamento de Risco do Pedestre ao Atraversaar a Rua: Um Estudo com Universitarios. Transporte: Teoria e Aplicaçao 2 (1), 19-41.

Trimpop, R.M., 1994. The psychology of risk-taking behavior Elsevier/North Holland, New York/Amsterdam.

West, R., French, D., Kemp, R., Elander, J., 1993. Direct observations of driving, self-reports of driver behaviour, and accident involvement. Ergonomics 36, 557-567.

Xie, C.-Q., Parker, D., 2002. A social psychological approach to driving violations in two Chinese cities. Transportation Research Part F: Traffic Psychology and Behaviour 5 (4), 293-308.

Yagil, D., 1998. Gender and age-related differences in attitudes toward traffic laws and traffic violations. Transportation Research Part F: Traffic Psychology and Behaviour 1, $123-$ 135.

Yagil, D., 2000. Beliefs, motives and situational factors related to pedestrians' self-reported behavior at signal-controlled crossings. Transportation Research Part F: Traffic Psychology and Behaviour 3 (1), 1-13.

Yildirim, Z., 2007. Religiousness, conservatism and their relationship with traffic behaviours. Middle East Technical University.

Zeedyk, M.S., Kelly, L., 2003. Behavioural observations of adult-child pairs at pedestrian crossings. Accident Analysis \& Prevention 35 (5), 771-776. 
Zhou, R., Horrey, W.J., 2010. Predicting adolescent pedestrians' behavioral intentions to follow the masses in risky crossing situations. Transportation Research Part F: Traffic Psychology and Behaviour 13 (3), 153-163.

Zhou, R., Horrey, W.J., Yu, R., 2009. The effect of conformity tendency on pedestrians' roadcrossing intentions in China: An application of the theory of planned behavior. Accident Analysis and Prevention 41, 491-497. 
Appendix

Short version of the PBS (23 items)(the numbers correspond to the item's place in the original version of the PBS)

Violation

I cross diagonally to save time (37)

I cross outside the pedestrian crossing even if there is one less than 50 meters away (40)

I cross the street even though the pedestrian light is red (17)

I cross even though the light is still green for vehicles (25)

\section{Error}

I cross the street between parked cars (35)

I start to cross on a pedestrian crossing and I finish crossing diagonally to save time (9)

I cross between vehicles stopped on the roadway in traffic jams (6)

I walk on the roadway to be next to my friends on the sidewalk or to overtake someone who is walking slower than I am (16)

Lapse

I forget to look before crossing because I am thinking about something else (36)

I forget to look before crossing because I want to join someone on the sidewalk on the other side (39)

I cross without looking because I am talking with someone (4)

I realize that I have crossed several streets and intersections without paying attention to traffic (22)

Aggressive

I get angry with another user and insult him (23)

I get angry with another user (pedestrian, driver, cyclist, etc.) and I yell at him (11)

I get angry with another user (pedestrian, driver, cyclist, etc.) and I make a hand gesture (28)

I get angry with a driver and hit his vehicle (15)

\section{Positive}

I let a car go by, even if I have the right-of-way, if there is no other vehicle behind it (34)

When I am accompanied by other pedestrians, I walk in single file on narrow sidewalks so as not to bother the pedestrians I meet (46)

I stop to let the pedestrians I meet by (21)

I walk on the right-hand side of the sidewalk so as not to bother the pedestrians I meet (5)

Filter

I walk for the pleasure of it (7)

I take public transportation (buses, metro, tramway, etc.) (32)

I walk because I have no other choice (19) 


\begin{tabular}{rcccccc}
\hline \multicolumn{6}{c}{ Age groups } \\
Gender & $15-25$ & $26-35$ & $36-45$ & $46-55$ & $\begin{array}{c}56 \\
\text { and above }\end{array}$ & Total \\
\hline Men & 37 & 43 & 20 & 15 & 11 & 126 \\
Women & 61 & 96 & 22 & 17 & 21 & 217 \\
Total & 98 & 139 & 42 & 32 & 32 & 343 \\
\hline \multicolumn{7}{r}{ Table 1. Numbers by gender for each age group }
\end{tabular}




\begin{tabular}{|c|c|c|c|c|c|c|c|c|}
\hline \multirow[b]{2}{*}{ Item (How often do you...) } & \multirow[b]{2}{*}{ M } & \multirow[b]{2}{*}{$\begin{array}{l}\mathrm{S} \\
\mathrm{D} \\
\end{array}$} & \multicolumn{6}{|c|}{ Distribution of responses (\%) } \\
\hline & & & 1 & 2 & 3 & 4 & 5 & 6 \\
\hline \multirow[t]{2}{*}{ I thank a driver who stops to let me cross } & 5. & 0. & 0. & 0. & 3. & 6. & 24 & 64 \\
\hline & 46 & 89 & 6 & 9 & 2 & 4 & .8 & .1 \\
\hline \multirow[t]{2}{*}{ I walk outdoors } & 5. & 1. & 0 & 3. & 8. & 12 & 28 & 46 \\
\hline & 06 & 12 & & 8 & 2 & .8 & .9 & .4 \\
\hline \multirow[t]{2}{*}{ I take public transportation (buses, metro, tramway, etc.) } & 4. & 1. & 8. & 11 & 12 & 10 & 12 & 44 \\
\hline & 39 & 77 & 7 & .7 & .5 & .5 & .2 & .3 \\
\hline \multirow[t]{2}{*}{ I walk without being accompanied } & 4. & 1. & 1. & 9. & 15 & 25 & 26 & 21 \\
\hline & 31 & 29 & 2 & 3 & .7 & .9 & .2 & .6 \\
\hline \multirow[t]{2}{*}{ I walk for the pleasure of it } & 4. & 1. & 6. & 13 & 17 & 17 & 22 & 22 \\
\hline & 03 & 55 & 4 & .4 & .5 & .8 & .7 & .2 \\
\hline \multirow{4}{*}{$\begin{array}{l}\text { I start to cross on a pedestrian crossing and I finish crossing diagonally to save } \\
\text { time } \\
\text { I cross between vehicles stopped on the roadway in traffic jams }\end{array}$} & 4. & 1. & 7 & 13 & 14 & 22 & 22 & 20 \\
\hline & 03 & 53 & & .1 & & .7 & .4 & .7 \\
\hline & 3. & 1. & 5. & 13 & 17 & 21 & 27 & 14 \\
\hline & 96 & 43 & 2 & .7 & .5 & 6 & .7 & .3 \\
\hline \multirow[t]{2}{*}{ I cross the street between parked cars } & 3. & 1. & 2. & 16 & 20 & 25 & 20 & 14 \\
\hline & 89 & 36 & 6 & & .4 & .9 & .7 & .3 \\
\hline \multirow{2}{*}{ I look at the traffic light and start crossing as soon as it turns red } & 3. & 1. & 8. & 19 & 16 & 18 & 20 & 17 \\
\hline & 78 & 59 & 2 & & & .7 & .4 & .8 \\
\hline \multirow[t]{2}{*}{ I stop to let the pedestrians I meet by } & 3. & 1. & 5. & 12 & 26 & 24 & 22 & 9. \\
\hline & 74 & 33 & 2 & .5 & .2 & .2 & .4 & 3 \\
\hline I cross the street even though the pedestrian light is red & 3. & 1. & 5. & 18 & 18 & 25 & 19 & 12 \\
\hline & 73 & 44 & 8 & .4 & .4 & .1 & .5 & .8 \\
\hline I cross diagonally to save time & 3. & 1. & 9. & 17 & 17 & 18 & 22 & 14 \\
\hline & 7 & 57 & 6 & .5 & .8 & .1 & .7 & .3 \\
\hline I cross outside the pedestrian crossing even if there is one less than 50 meters & 3. & 1. & 6. & 19 & 20 & 20 & 19 & 14 \\
\hline 1 & 69 & 49 & 1 & .8 & .4 & .4 & .2 & \\
\hline When I am accompanied by other pedestrians, I walk in single file on narrow & 3. & 1. & 9 & 19 & 18 & 20 & 21 & 12 \\
\hline sidewalks so as not to bother the pedestrians I meet & 63 & 52 & & & .1 & .4 & .3 & .2 \\
\hline I walk in covered areas (such as shopping centers) & 3. & 1. & 3. & 19 & 26 & 23 & 17 & 9. \\
\hline & 61 & 34 & 8 & & .8 & .3 & .2 & 9 \\
\hline I walk on the right-hand side of the sidewalk so as not to bother the pedestrians I & 3. & 1. & 15 & 14 & 17 & 17 & 22 & 12 \\
\hline meet & 57 & 63 & .2 & & .5 & .8 & .7 & .8 \\
\hline I let a car go by, even if I have the right-of-way, if there is no other vehicle & 3. & 1. & 12 & 19 & 20 & 20 & 15 & 11 \\
\hline behind it & 43 & 54 & & .5 & .7 & .7 & .7 & .4 \\
\hline On a two-way street, I cross the first part and wait in the middle of the roadway & 3. & 1. & 12 & 19 & 19 & 22 & 16 & 9. \\
\hline to cross the second part & 4 & 52 & .8 & .2 & .2 & .4 & 6 & 6 \\
\hline I walk accompanied by other people & 3. & 1. & 4. & 20 & 35 & 20 & 13 & 5. \\
\hline & 34 & 22 & 7 & .4 & .6 & .7 & .4 & 2 \\
\hline I walk on the roadway to be next to my friends on the sidewalk or to overtake & 3. & 1. & 9. & 23 & 20 & 24 & 16 & 6. \\
\hline someone who is walking slower than I am & 34 & 41 & 6 & & .1 & .2 & .9 & 1 \\
\hline I cross while talking on my cell phone or listing to music on my headphones & 3. & 1. & 23 & 19 & 13 & 17 & 13 & 12 \\
\hline & 14 & 72 & .6 & .8 & .4 & .2 & .7 & .2 \\
\hline I cross even though the light is still green for vehicles & 3. & 1. & 11 & 28 & 22 & 21 & 11 & 4. \\
\hline & 07 & 35 & .7 & & .4 & .9 & .7 & 4 \\
\hline I walk because I have no other choice & 3. & 1. & 14 & 26 & 23 & 16 & 11 & 7. \\
\hline & 06 & 47 & .6 & .5 & .3 & 6 & .4 & 6 \\
\hline I start walking across the street, but I have to run the rest of the way to avoid & 2. & 1. & 17 & 30 & 17 & 21 & 9. & 3. \\
\hline oncomin & 86 & 39 & .5 & .6 & .2 & .3 & 6 & 8 \\
\hline I walk on the curb & 2. & 1. & 17 & 29 & 28 & 16 & 6. & 2. \\
\hline & 72 & 24 & .5 & .2 & .3 & 6 & 1 & 3 \\
\hline I avoid using pedestrian bridges or underpasses, even if one is located nearby & 2. & 1. & 27 & 30 & 15 & 11 & 8. & 5. \\
\hline & 61 & 50 & .4 & .9 & .7 & .4 & 7 & 8 \\
\hline I cross even though obstacles (parked vehicles, buildings, trees, trash bins, etc.) & 2. & 1. & 21 & 33 & 21 & 14 & 7 & 1. \\
\hline obstruct visibility & 56 & 24 & .3 & .8 & 9 & .9 & & 2 \\
\hline I cross even if vehicles are coming because I think they will stop for me & 2. & 1. & 25 & 36 & 16 & 12 & 6. & 2. \\
\hline & 46 & 31 & .4 & .4 & .9 & & 7 & 6 \\
\hline I cross without looking, following other people who are crossing & 2. & 1. & 31 & 28 & 21 & 12 & 3. & 2. \\
\hline & 37 & 29 & .5 & .3 & & .8 & 8 & 6 \\
\hline I lose my way because I get lost in my thoughts & 2. & 1. & 31 & 37 & 12 & 9. & 7 & 2. \\
\hline & 31 & 32 & .5 & & .5 & 6 & & 3 \\
\hline I realize that I do not remember the route I have just taken & 2. & 1. & 36 & 32 & 12 & 10 & 6. & 2 \\
\hline
\end{tabular}




\begin{tabular}{|c|c|c|c|c|c|c|c|c|}
\hline & 24 & 32 & .2 & .7 & .2 & .5 & 4 & \\
\hline \multirow[t]{2}{*}{ I get angry with another user (pedestrian, driver, cyclist, etc.) and I yell at him } & 2. & 1. & 41 & 29 & 10 & 10 & 5. & 1. \\
\hline & 15 & 31 & .4 & .7 & .8 & .8 & 5 & 7 \\
\hline \multirow[t]{2}{*}{ I walk in a way that forces other pedestrians to let me through } & 2. & 1. & 35 & 37 & 16 & 7. & 2. & 1. \\
\hline & 09 & 11 & & .3 & .6 & 3 & 6 & 2 \\
\hline \multirow[t]{2}{*}{ I hit a pedestrian or an obstacle because I am not paying attention } & 2. & 1. & 32 & 47 & 10 & 7. & 1. & 0 . \\
\hline & 02 & 01 & .1 & .5 & .5 & 3 & 7 & 9 \\
\hline \multirow[t]{2}{*}{ I take passageways forbidden to pedestrians to save time } & 1. & 1. & 46 & 30 & 10 & 6. & 4. & 1. \\
\hline & 95 & 20 & .6 & .9 & .5 & 4 & 1 & 5 \\
\hline \multirow[t]{2}{*}{ I walk on cycling paths when I could walk on the sidewalk } & 1. & 1. & 47 & 31 & 9 & 7. & 2. & 1. \\
\hline & 9 & 14 & .5 & .8 & & 9 & 6 & 2 \\
\hline \multirow[t]{2}{*}{ I cross very slowly to annoy a driver } & 1. & 1. & 58 & 22 & 8. & 6. & 2. & 1. \\
\hline & 76 & 14 & .3 & .7 & 5 & 7 & 6 & 2 \\
\hline \multirow{2}{*}{$\begin{array}{l}\text { I realize that I have crossed several streets and intersections without paying } \\
\text { attention to traffic }\end{array}$} & 1. & 0. & 50 & 33 & 9. & 5 & 0 . & 0 . \\
\hline & 75 & 98 & .1 & .8 & 3 & & 9 & 9 \\
\hline \multirow{2}{*}{$\begin{array}{l}\text { I get angry with another user (pedestrian, driver, cyclist, etc.) and I make a hand } \\
\text { gesture }\end{array}$} & 1. & 1. & 58 & 23 & 9. & 6. & 2 & 0. \\
\hline & 71 & 04 & & .6 & 9 & 1 & & 3 \\
\hline \multirow[t]{2}{*}{ I forget to look before crossing because I am thinking about something else } & 1. & 0. & 52 & 35 & 7 & 2. & 1. & 0 . \\
\hline & 66 & 90 & .5 & .9 & & 6 & 5 & 6 \\
\hline \multirow{2}{*}{ I cross without looking because I am talking with someone } & 1. & 0. & 54 & 33 & 7 & 4. & 0 . & 0 . \\
\hline & 64 & 86 & .2 & .8 & & 1 & 6 & 3 \\
\hline \multirow{4}{*}{$\begin{array}{l}\text { I deliberately walk on the roadway when I could walk on the sidewalk or on the } \\
\text { shoulder } \\
\text { I get angry with another user and insult him }\end{array}$} & 1. & 0. & 60 & 24 & 7. & 4. & 1. & 0 . \\
\hline & 63 & 98 & .9 & .5 & 9 & 7 & 5 & 6 \\
\hline & 1. & 1. & 63 & 23 & 6. & 2. & 2. & 1. \\
\hline & 62 & 05 & .3 & .6 & 7 & 6 & 3 & 5 \\
\hline \multirow{4}{*}{$\begin{array}{l}\text { I forget to look before crossing because I want to join someone on the sidewalk } \\
\text { on the other side } \\
\text { I run across the street without looking because I am in a hurry }\end{array}$} & 1. & 0. & 58 & 30 & 7. & 2. & 1. & 0 \\
\hline & 59 & 86 & & & 9 & 6 & 5 & \\
\hline & 1. & 0. & 70 & 21 & 4. & 3. & 0. & 0 . \\
\hline & 43 & 80 & & .9 & 1 & 5 & 3 & \\
\hline \multirow[t]{2}{*}{ I get angry with a driver and hit his vehicle } & 1. & 0. & 79 & 13 & 2. & 2 & 2. & 0 \\
\hline & 34 & 83 & .3 & .7 & 6 & & 3 & \\
\hline \multirow[t]{2}{*}{ I walk on bus lanes when I could walk on the sidewalk } & 1. & 0. & 77 & 16 & 4. & 0. & 1. & 0 \\
\hline & 33 & 71 & & .6 & 4 & 9 & 2 & \\
\hline
\end{tabular}

Table 2. PBS behavior items: means, standard deviations and distribution of responses 


\begin{tabular}{|c|c|c|c|c|}
\hline \multirow[t]{2}{*}{ Item (How often do you...) } & \multicolumn{2}{|l|}{ Factor } & \multicolumn{2}{|c|}{ Factor Factor } \\
\hline & 1 & Factor 2 & 3 & \\
\hline I cross diagonally to save time & .81 & & & \\
\hline I cross outside the pedestrian crossing even if there is one less than 50 meters away & .77 & & & \\
\hline I cross the street even though the pedestrian light is red & .77 & & & \\
\hline I cross the street between parked cars & .74 & & & \\
\hline $\begin{array}{l}\text { I start to cross on a pedestrian crossing and I finish crossing diagonally to save } \\
\text { time }\end{array}$ & .73 & & & \\
\hline I cross even though the traffic light is still green for vehicles & 70 & & & \\
\hline I cross between vehicles stopped on the roadway in traffic jams & 65 & & & \\
\hline $\begin{array}{l}\text { I walk on the roadway to be next to my friends on the sidewalk or to overtake } \\
\text { someone who is walking slower than I am }\end{array}$ & .61 & & & \\
\hline I look at the traffic light and start crossing as soon as it turns red & .57 & & & \\
\hline $\begin{array}{l}\text { I start walking across the street, but I have to run the rest of the way to avoid } \\
\text { oncoming vehicles }\end{array}$ & .51 & & & \\
\hline $\begin{array}{l}\text { I deliberately walk on the roadway when I could walk on the sidewalk or on the } \\
\text { shoulder }\end{array}$ & .49 & & & \\
\hline I walk on the curb & 49 & & & \\
\hline I take passageways forbidden to pedestrians to save time & .49 & & & \\
\hline I cross while talking on my cell phone or listing to music on my headphones & .45 & & & \\
\hline $\begin{array}{l}\text { On a two-way street, I cross the first part and wait in the middle of the roadway to } \\
\text { cross the second part }\end{array}$ & .38 & & & \\
\hline I forget to look before crossing because I am thinking about something else & & .79 & & \\
\hline $\begin{array}{l}\text { I forget to look before crossing because I want to join someone on the sidewalk on } \\
\text { the other side }\end{array}$ & & .74 & & \\
\hline I cross without looking because I am talking with someone & & .70 & & \\
\hline $\begin{array}{l}\text { I realize that I have crossed several streets and intersections without paying } \\
\text { attention to traffic }\end{array}$ & & .66 & & \\
\hline I cross without looking, following other people who are crossing & & .66 & & \\
\hline I hit a pedestrian or an obstacle because I am not paying attention & & .54 & & \\
\hline I realize that I do not remember the route I have just taken & & .36 & & \\
\hline I get angry with another user and insult him & & & .76 & \\
\hline I get angry with another user (pedestrian, driver, cyclist, etc.) and I yell at him & & & .74 & \\
\hline $\begin{array}{l}\text { I get angry with another user (pedestrian, driver, cyclist, etc.) and I make a hand } \\
\text { gesture }\end{array}$ & & & .71 & \\
\hline I get angry with a driver and hit his vehicle & & & .57 & \\
\hline I cross very slowly to annoy a driver & & & .40 & \\
\hline I let a car go by, even if I have the right-of-way, if there is no other vehicle behind $i$ & & & & .61 \\
\hline $\begin{array}{l}\text { When I am accompanied by other pedestrians, I walk in single file on narrow } \\
\text { sidewalks so as not to bother the pedestrians I meet }\end{array}$ & & & & .61 \\
\hline I stop to let the pedestrians I meet by & & & & .49 \\
\hline $\begin{array}{l}\text { I walk on the right-hand side of the sidewalk so as not to bother the pedestrians I } \\
\text { meet }\end{array}$ & & & & .47 \\
\hline I thank a driver who stops to let me cross & & & & .39 \\
\hline$\%$ of variance explained & 21.09 & 7.73 & 6.17 & 4.84 \\
\hline
\end{tabular}

Table 3. Principal axis factor analysis of the 40 PBS behavior items (Varimax rotation) 


\begin{tabular}{cccc}
\hline & Lapses & $\begin{array}{c}\text { Aggressive } \\
\text { behaviors }\end{array}$ & $\begin{array}{c}\text { Positive } \\
\text { behaviors }\end{array}$ \\
\hline $\begin{array}{c}\text { Transgression } \\
\text { Lapses }\end{array}$ & $.39^{* * *}$ & $.21^{* *}$ & -.01 \\
Aggressive behaviors & & $.16^{* *}$ & $-.11^{*}$ \\
\hline
\end{tabular}

Table 4. Partial correlations between the scores on the driver behavior questionnaire with checks on the gender and age variables

$$
* \mathrm{p}<.05 ; * * \mathrm{p}<.01
$$


Developing a self-reporting method to measure pedestrian behaviors at all ages

\begin{tabular}{|c|c|c|c|c|c|c|c|c|}
\hline $\begin{array}{l}\text { Age } \\
\text { group }\end{array}$ & Gender & Transgression & Offence & Error & Lapses & Aggression & Positive & $\mathrm{N}$ \\
\hline \multirow[t]{6}{*}{$15-25$} & Men & 46.27 (11.76) & 23.70 & 22.57 & 12.54 & $7.70(3.49)$ & 18.14 & 37 \\
\hline & & & $(6.83)$ & (5.51) & $(5.19)$ & & $(4.06)$ & \\
\hline & Women & $43.49(11.25)$ & 22.13 & 21.36 & 13.80 & $8.20(3.62)$ & 19.79 & 61 \\
\hline & & & $(6.95)$ & (5.10) & $(4.09)$ & & $(3.95)$ & \\
\hline & Total & 44.54 (11.47) & 22.72 & 21.82 & 13.33 & $8.01(3.56)$ & 19.16 & 98 \\
\hline & & & $(6.91)$ & (5.26) & $(4.55)$ & & $(4.05)$ & \\
\hline \multirow[t]{6}{*}{$26-35$} & Men & $48.16(10.14)$ & 25.02 & 23.14 & 11.58 & 7.79 (2.97) & 19.56 & 43 \\
\hline & & & $(6.46)$ & (4.82) & $(3.98)$ & & $(3.93)$ & \\
\hline & Women & $43.11(11.74)$ & 21.99 & 21.13 & 13.01 & $9.18(3.83)$ & 19.64 & 96 \\
\hline & & & $(6.59)$ & (5.88) & $(5.41)$ & & $(4.56)$ & \\
\hline & Total & 44.68 (11.47) & 22.93 & 21.75 & 12.57 & $8.75(3.64)$ & 19.61 & 139 \\
\hline & & & $(6.68)$ & (5.64) & $(5.04)$ & & $(4.36)$ & \\
\hline \multirow[t]{6}{*}{$36-45$} & Men & $42.40(9.39)$ & 21.60 & 20.80 & 10.70 & $9.95(4.95)$ & 20.05 & 20 \\
\hline & & & $(4.66)$ & (5.14) & $(4.97)$ & & $(3.75)$ & \\
\hline & Women & $38.68(13.53)$ & 18.64 & 20.05 & 13.00 & $9.32(3.67)$ & 20.23 & 22 \\
\hline & & & (6.95) & (7.09) & $(5.47)$ & & $(3.60)$ & \\
\hline & Total & $40.45(11.75)$ & 20.05 & 20.40 & 11.91 & $9.62(4.28)$ & 20.14 & 42 \\
\hline & & & $(6.09)$ & (6.18) & $(5.30)$ & & $(3.63)$ & \\
\hline \multirow[t]{6}{*}{$46-55$} & Men & $34.47(11.30)$ & 17.07 & 17.40 & 10.47 & $8.47(3.25)$ & 19.87 & 15 \\
\hline & & & $(6.02)$ & (5.64) & $(2.61)$ & & $(4.85)$ & \\
\hline & Women & $34.53(13.13)$ & 16.76 & 17.76 & 11.12 & $8.06(3.29)$ & 22.88 & 17 \\
\hline & & & $(7.21)$ & (6.46) & $(4.77)$ & & $(3.16)$ & \\
\hline & Total & $34.50(12.11)$ & 16.91 & 17.59 & 10.81 & $8.25(3.22)$ & 21.47 & 32 \\
\hline & & & $(6.57)$ & (5.99) & $(3.86)$ & & $(4.26)$ & \\
\hline \multirow{6}{*}{$\begin{array}{l}56 \text { et } \\
\text { plus }\end{array}$} & Men & 37.09 (11.59) & 19.18 & 17.91 & 12.18 & $7.91(3.75)$ & 20.55 & 11 \\
\hline & & & $(7.14)$ & $(4.85)$ & $(5.64)$ & & $(3.72)$ & \\
\hline & Women & $34.86(10.42)$ & 18.00 & 16.86 & 11.62 & $8.90(3.08)$ & 20.95 & 21 \\
\hline & & & $(5.92)$ & (5.78) & $(3.04)$ & & $(3.43)$ & \\
\hline & Total & $35.63(10.70)$ & 18.41 & 17.22 & 11.81 & $8.56(3.30)$ & 20.81 & 32 \\
\hline & & & $(6.27)$ & (5.42) & $(4.04)$ & & $(3.48)$ & \\
\hline Total & Men & $44.10(11.65)$ & 22.63 & 21.46 & 11.64 & $8.20(3.63)$ & 19.34 & 126 \\
\hline
\end{tabular}


Developing a self-reporting method to measure pedestrian behaviors at all ages

\begin{tabular}{cccccccc}
\hline & & $(6.79)$ & $(5.52)$ & $(4.55)$ & & $(4.06)$ \\
Women & $41.30(12.15)$ & 20.89 & 20.41 & 12.95 & $8.80(3.65)$ & 20.12 & 217 \\
& & $(6.93)$ & $(5.98)$ & $(4.86)$ & & $(4.17)$ & \\
Total & $42.33(12.03)$ & 21.53 & 20.79 & 12.47 & $8.58(3.65)$ & 19.83 & 343 \\
& & $(6.92)$ & $(5.83)$ & $(4.79)$ & & $(4.14)$ & \\
\hline
\end{tabular}

Table 5. Means (and standard deviations) of the scores on the PBS for each gender, the five age groups and the total sample 